Available online at https://jurnal.stmikroyal.ac.id/index.php/jurdimas

\title{
PELATIHAN MENDELEY DAN GRAMMARLY DALAM PENULISAN RISET BAGI MAHASISWA DI KOTA PALEMBANG
}

\author{
Try Wulandari ${ }^{1^{*}}$, Emilda $^{1}$, Shafiera Lazuarni ${ }^{1}$ \\ ${ }^{1}$ Program Studi Manajemen Universitas Indo Global Mandiri \\ email:*wulan@uigm.ac.id
}

\begin{abstract}
Writing is an activity to express ideas or ideas that are in someone's mind. everyone must have an idea or idea, but not everyone is able to write down these ideas. some even think that writing requires a high educational background. students, for example, because they are deemed to have taken higher education and are accused of writing from assignments given by the lecturer. The low number of writers in Indonesia means that scientific publications in Indonesia are still inadequate. In 2019, Indonesia succeeded in publishing the most scientific papers when compared to other ASEAN countries such as Singapore, Malaysia and Thailand. However, this figure is still insufficient, so that efforts are needed to increase the number and quality of good research writing. This activity aims to help make it happen. The target of this activity is students, both from public and private universities in Palembang City. The methods used in this PkM activity were material presentation, practical assistance, and discussion together. Based on the results of the questionnaire answers from 36 participants, the majority of participants agreed that this activity provided new knowledge and information in the topic of research writing. In addition, most of the participants also found this training interesting and made them excited to write a good research. So it can be concluded that the majority of students are not proficient in using Mendeley and Grammarly software and feel that both software can make writing their research easier.
\end{abstract}

Keywords: grammarly; mendeley; research; training; writing

\begin{abstract}
Abstrak: Menulis merupakan suatu kegiatan untuk mengungkapkan gagasan atau gagasan yang ada di benak seseorang. setiap orang pasti punya ide atau ide, tapi tidak semua orang mampu menuliskan ide-ide tersebut. bahkan ada yang beranggapan bahwa menulis membutuhkan latar belakang pendidikan yang tinggi. mahasiswa, misalnya, karena dianggap telah menempuh pendidikan tinggi dan dituduh menulis dari tugas-tugas yang diberikan dosen. Rendahnya jumlah penulis di Indonesia membuat publikasi ilmiah di Indonesia masih kurang mencukupi. Pada tahun 2019, Indonesia berhasil menerbitkan karya ilmiah terbanyak jika dibandingkan dengan negara ASEAN lainnya seperti Singapura, Malaysia, dan Thailand. Namun angka tersebut masih belum mencukupi, sehingga diperlukan upaya untuk meningkatkan jumlah dan kualitas penulisan penelitian yang baik. Kegiatan ini bertujuan untuk membantu mewujudkannya. Sasaran kegiatan ini adalah para mahasiswa, baik dari perguruan tinggi negeri maupun perguruan tinggi swasta di Kota Palembang. Metode yang digunakan dalam kegiatan PkM ini adalah Pelatihan. Berdasarkan hasil jawaban kuisioner dari 36 peserta, mayoritas peserta sepakat bahwa kegiatan ini memberikan pengetahuan dan informasi baru dalam topik penulisan penelitian. Selain itu, sebagian besar peserta juga menganggap pelatihan ini menarik dan membuat mereka bersemangat untuk menulis penelitian dengan baik. Maka dapat disimpulkan bahwa mayoritas mahasiswa belum mahir menggunakan software Mendeley dan Grammarly dan merasakan bahwa kedua software tersebut dapat mempermudah penulisan riset mereka.
\end{abstract}

Kata kunci: grammarly; mendeley; pelatihan; penulisan; riset 
Available online at https://jurnal.stmikroyal.ac.id/index.php/jurdimas

\section{PENDAHULUAN}

Menulis merupakan kegiatan untuk menuangkan ide-ide atau gagasangagasan yang ada di dalam fikiran penulis ke dalam kalimat-kalimat atau paragraph (Festiyed, 2015). Faktanya, banyak masyarakat yang mempunyai gagasan dan ingin merangkainya dengan kata-kata namun sulit. Hal ini dikarenakan untuk menulis diperlukannya keahlian atau soft skill. Bagi beberapa orang, menulis juga hanya diperuntukkan untuk beberapa orang saja, seperti yang berpendidikan atau setidaknya pernah duduk di bangku kuliah perguruan tinggi. Argumen ini mungkin muncul karena para mahasiswa sudah terbiasa diberi tugas berupa tulisan atau makalah selama kurang lebih empat tahun berkuliah. Mahasiswa juga sering diminta untuk membuat karya tulis ilmiah, hingga menulis skripsi sebagai salah satu syarat kelulusan (Melfianora, 2019). Sehingga untuk menulis akan lebih mudah bagi para mahasiswa. Selain sebagai salah satu syarat kelulusan, pembuatan karya tulis atau skripsi diharapakan mampu melatih mahasiswa untuk mengemas pemikiran-pemikirannya serta hasil temuan secara logis, detail dan sistematis. Tentunya, skripsi tersebut juga akan diterbitkan. Meskipun tidak diperlukan pendidikan khusus, menulis tetap memerlukan teknik-teknik tertentu. Hal ini bertujuan agar pesan atau ide yang ingin disampaikan dapat dipahami dengan mudah oleh pembaca dan pembaca merasa tertarik untuk menyelesaikan membaca tulisan tersebut.

Menulis juga memiliki manfaat yang baik bagi tubuh dan fikiran penulis. Dilansir dari laman hallosehat.com setidaknya ada enam manfaat dari kegiatan menulis seperti: membantu memulihkan emosi, membuat penulis lebih terorganisir, membantu untuk tertidur lebih baik, membantu dalam kemampuan berbicara lebih lancar, hingga membuat pikiran dan kondisi tubuh lebih baik. Tidak hanya itu, menulis juga terbukti mampu mengubah cara berfikir pasien kanker akan penyakit yang dideritanya. Dengan menulis, para pasien merasa emosinya lebih stabil, dan lebih ikhlas dalam menerima kondisinya (Rudystina, 2020).

Ketika penulis menuangkan fikiran-fikiran yang ada dibenaknya dan emosinya, maka proses penyembuhan akan menjadi lebih cepat. Sebuah studi dari Selandia Baru telah membuktikan bahwa menulis isi pikiran dan isi hati setelah peristiwa traumatis terbukti akan membuat luka fisik lebih cepat sembuh. Hal ini dibuktikan dengan keterlibatan seorang peserta yang pernah mengalami tindakan biopsi kulit, diminta untuk menulis catatan mengenai perasaan, keyakinan atau apapun yang Ia rasakan dan miliki dalam pikirannya. Dua minggu kemudian para peneliti mendapati bahwa ada kemajuan bekas luka yang lebih cepat dibandingkan peserta yang tidak menulis.

Menurut jurnal The Oncologist, tulisan yang berisikan tentang ekspresi para pasien terbukti dapat membantu pasien kanker dengan cara mengubah cara mereka berfikir, membuat mereka lebih ikhlas menerima keadaan, hingga meningkatkan kualitas hidup para pasien (Mulia, \& Gunawan, 2018). Terlebih lagi, penelitian ini juga menyimpulkan bahwa kegiatan menulis tidak harus memakan waktu yang panjang, menulis dalam durasi 20 menit juga sudah dapat membantu cara berfikir para penulis tentang penyakit yang mereka derita. Oleh karena itu, sangat disayangkan apabila kegiatan menulis justru dianggap sebagai kegiatan yang menyusahkan, memer- 
Available online at https://jurnal.stmikroyal.ac.id/index.php/jurdimas

lukan Pendidikan khusus bahkan dianggap seperti beban oleh penulis.

Berdasarkan data dari Kementerian Riset, Tekonologi, dan Perguruan Tinggi (Kemenristekdikti), jumlah publikasi hasil penelitian ataupun pengabdian kepada masyarakat saat ini sangat jauh dari target yang diharapkan. Pada tahun 2019, jumlah publikasi ilmiah di Indonesia mencapai 33.177 publikasi (Brodjonegoro, 2019). Angka ini merupakan angka terbesar bila dibandingkan dengan tahun-tahun sebelumnya atau bahkan lebih banyak bila dibandingkan dengan negara Malaysia dan Singapura. Negara Malaysia menghasilkan 32.952 publikasi pada tahun 2019 dimana angka ini berada di bawah angka publikasi di Indonesia. Sedangkan untuk negara Singapura, ada 22.500 publikasi dan ada 18.000 publikasi di negara Thailand. Bila dibandingkan dengan ketiga negara tersebut, Indonesia berada di peringkat pertama dengan hasil publikasi terbanyak di negara ASEAN.

Sementara Malaysia berada di bawah Indonesia dengan jumlah 32.952 publikasi. Adapun, Singapura dan Thailand masing-masing memiliki 22.500 dan 18.000 publikasi ilmiah. Akan tetapi, angka ini masih belum cukup. Menurut Menristekdikti Mohamad Nasir, jumlah publikasi saat ini tidak sebanding dengan banyaknya jumlah mahasiswa/i serta dosen-dosen aktif di Indonesia (Januarius, 2019). Selain kuantitas, kualitas dari penulisan juga perlu dipertimbangkan dan teru ditingkatkan. Para mahasiswa diharapkan untuk selalu mengasah keterampilan menulisnya selagi di perguruan tinggi sehingga nantinya akan menghasilkan karyakarya yang banyak, menarik, dan bermanfaat bagi masyarakat luas.

Tujuan dari kegiatan pengabdian kepada masyarakat ini yaitu dapat mem- bantu mahasiswa untuk menambah ilmu dan informasi terkait penulisan riset yang baik. Selain itu, kegian PKM ini diharapkan mampu mengubah pola fikir atau mindset mahasiswa bahwa menulis itu menyenangkan, tidak susah dan juga memiliki banyak manfaat untuk jasmani dan rohani penulis.

Hasil yang diharapkan melalui kegiatan PkM ini adalah para mahasiswa menjadi lebih bersemangat untuk melakukan dan menulis riset, serta berperan aktif dalam meningkan jumlah dan mutu publikasi di Indonesia.

\section{METODE}

Kegiatan $\mathrm{PkM}$ ini berlangsung selama satu hari di Telkomsel Smart Office Palembang yang belokasikan di Jl. Veteran No.88A, Kuto Batu, Kec. Ilir Tim. II, Kota Palembang, Sumatera Selatan 30114. Kegiatan ini diikuti oleh 36 peserta yang merupakan para mahasiswa dari beberapa universitas di Palembang. Untuk menunjang acara kegiatan PkM ini dan mencapai tujuannya, maka kegiatan PkM menerapkan beberapa metode, diantaranya:

Pendidikan Masyarakat, metode ini digunakan terlebih dahulu karena agar para mahasiswa memahami kebutuhan publikasi karya ilmiah di Indonesia saat ini dan beberapa manfaat dari menulis. Para mahasiswa juga akan diberikan beberapa contoh dan trik untuk menemukan ide-ide atau topik-topik menarik untuk dijadikan riset. Tujuannya adalah agar para mahasiswa memahami betul peranan mereka sebagai masa depan bangsa dan juga diharapkan agar merasa termotivasi untuk melakukan riset karena menulis memberikan banyak manfaat untuk Kesehatan jasmani dan rohani. 
Available online at https://jurnal.stmikroyal.ac.id/index.php/jurdimas

Pendampingan Praktek, metode selanjutnya yaitu para mahasiswa dipersilahkan untuk melakukan praktek masing-masing dan akan didampingin oleh tim PkM. Pada sesi ini, para mahasiswa akan memulai dari mengunduh atau meng install software Mendeley dan Grammarly, lalu membuat akun. Mahasiswa juga akan diminta untuk menulis paling sedikit tiga paragraf dan langsung menggunakan Mendeley dan Grammarly dalam menulis.

Diskusi: selagi para mahasiswa mencoba mempraktekkan yang sudah diajarkan, para tim PkM membuka sesi tanya jawab untuk berdiskusi dan memberikan solusi bagi para mahasiswa yang mengalami kesulitan selama kegiatan praktek. Sesuai dengan judulnya, PkM ini bertujuan untuk membantu para mahasiswa menulis riset dengan lebih baik dan efisien, yaitu dengan menggunakan software Grammarly dan Mendeley. Sehingga, pada akhirnya, karya ilmiah yang dihasilkan bukan hanya berjumlah banyak namun juga berkualitas untuk dipublikasikan.

\section{PEMBAHASAN}

Kegiatan PkM ini terbagi menjadi dua sesi, yaitu sesi pemaparan materi dan sesi pelatihan atau praktek langsung oleh para peserta.

\section{Pemaparan Materi}

Sebelum mahasiswa diajak untuk praktek sendiri, para mahasiswa diberikan materi terlebih dahulu. Materimateri yang akan disampaikan oleh Try Wulandari, S.E., M.Fin selaku pemateri adalah manfaat melakukan kegiatan menulis, perkembangan data publikasi hasil penelitian, serta bagaimana mencari ide atau topik-topik menarik untuk di tulis.

Kegiatan ini berkerja sama dengan telkomsel sebagai host tempat penyelenggaraan acara dan juga bantuan dua dosen dari Fakultas Ekonomi Universitas Indo Global Mandiri.

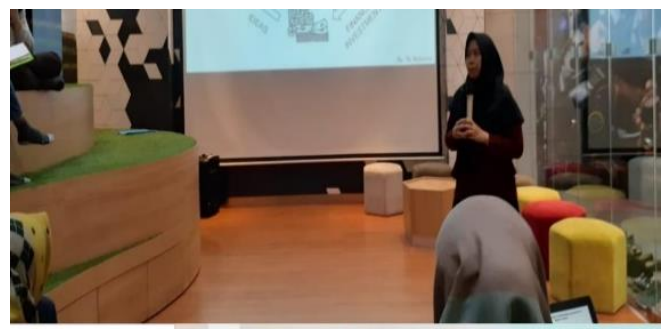

Gambar 1. pemaparan materi

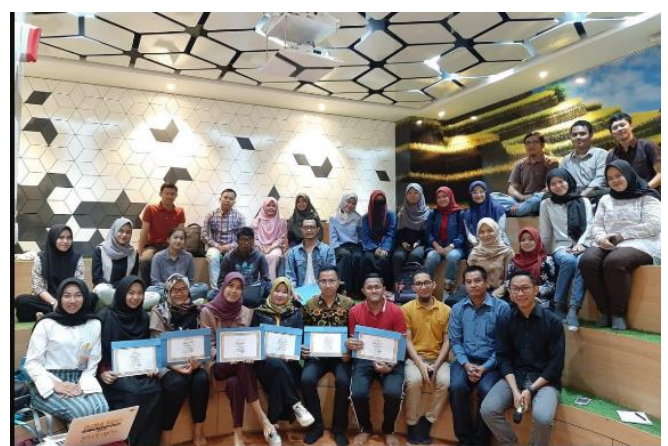

Gambar 2. tim PKM bersama peserta

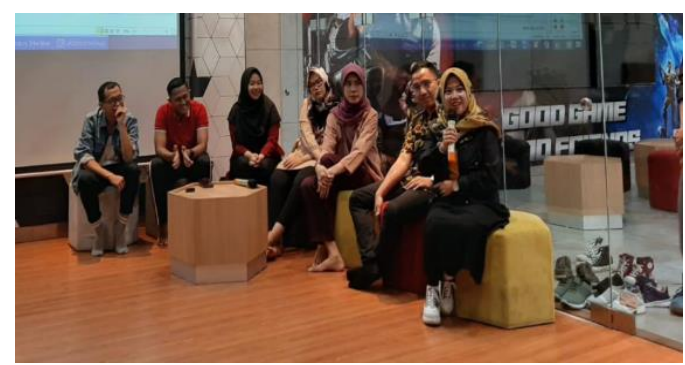

Gambar 3. para pemateri dalam sesi diskusi

\section{Pelatihan Praktek Langsung}

Pada sesi selanjutnya, para peserta diminta untuk membuat tulisan paling sedikit tiga paragraf untuk menguji pemahaman terhadap materi yang sudah disampaikan. Pada sesi ini juga para mahasiswa akan mengunduh software Mendeley dan Grammarly lalu langsung praktek menggunakan kedua 
Available online at https://jurnal.stmikroyal.ac.id/index.php/jurdimas

software tersebut untuk membantu proses penulisan tulisan singkat bertemakan bebas.

Diakhir acara, para peserta diminta untuk mengisi kuesioner sebagai data evaluasi kegiatan. Berikut hasil jawaban yang diterima dari 36 responden.

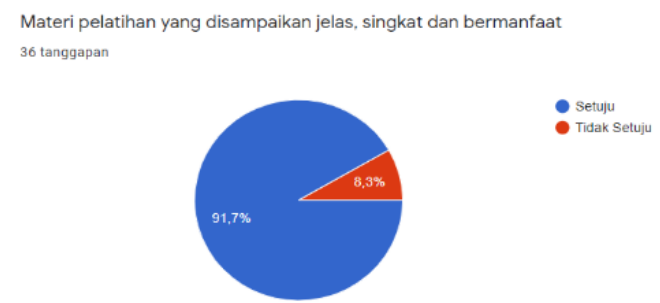

Gambar 4. hasil jawaban responden

$$
\text { Berdasarkan diagram pada }
$$
gambar 4, dapat disimpulkan bahwa mayoritas peserta setuju bahwa pelatihan ini memberikan manfaat dan disampaikan secara jelas dan juga singkat. Selain itu, mayoritas peserta juga merasa bahwa selain bermanfaat, pelatihan ini juga menarik.

$$
\text { Pelatihan yang diberikan menarik dan bermanfaat bagi saya }
$$$$
36 \text { tanggapan }
$$

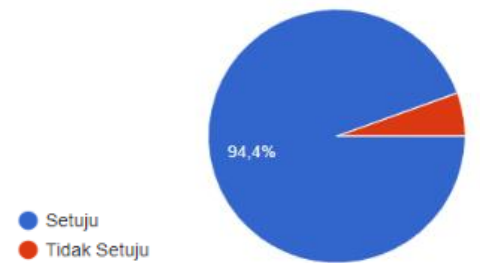

Gambar 4. hasil jawaban responden

Tujuan dari pelatihan ini agar dapat membantu para mahasiswa untuk lebih bersemangat lagi dalam menulis riset dan menghasilkan karya-karya ilmiah yang banyak dan berkualitas. Pencapaian tujuan ini dapat dilihat melalui feedback peserta melalui pertanyaan "pelatihan ini membantu saya un- tuk menulis riset lebih baik". Berikut hasil jawaban dari responden.

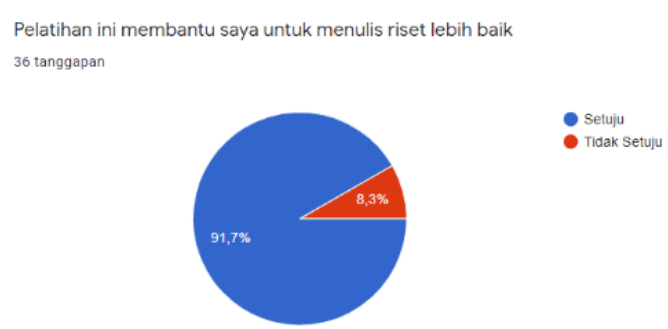

Gambar 5. hasil jawaban responden

Bila dilihat dari jawaban pada gambar 5, 91,7\% peserta merasa terbantu dengan adanya kegitan ini. Kegiatan ini dirasa mampu membantu peserta untuk menulis dan menghasilkan riset yang baik dan berkualitas. Sehingga, dapat dikatakan bahwa tujuan dari kegiatan ini tercapai.

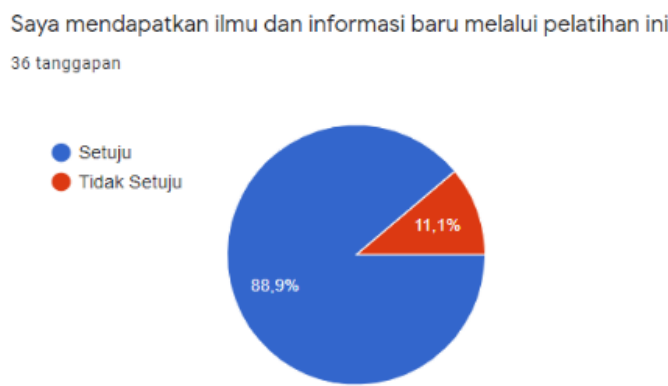

Gambar 6. hasil jawaban responden

Berdasarkan diagram pada gambar 6 , terdapat $88,9 \%$ peserta yang setuju bahwa pelatihan ini memberikan informasi dan ilmu baru bagi mereka. Sehingga, secara garis besar dapat disimpulkan bahwa kegiatan pengabdian kepada masyarakat ini berjalan dengan lancar dan berhasil mencapai tujuan yang sudah ditetapkan, yaitu memberikan informasi dan ilmu kepada mahasiswa sehingga mereka akan lebih termotivasi dan bersemangat untuk menulis riset penelitian. 
Available online at https://jurnal.stmikroyal.ac.id/index.php/jurdimas

\section{SIMPULAN}

Berdasarkan data feedback yang diterima oleh tim kegiatan ini melalui data kuesioner, dapat disimpulkan bahwa kegiatan berjalan dengan lancar dan sukses. Hal ini dicerminkan dari jawaban-jawaban para peserta dimana mayoritas dari peserta setuju bahwa pelatihan ini memberikan informasi dan ilmu baru bagi mereka dibidang penulisan riset. Selain itu, para peserta juga merasa bahwa pelatihan ini menarik dan memberikan mereka semangat untuk melakukan riset, menulisnya lalu juga mempublikasikan hasil risetnya. Berdasarkan feedback dan antusias yang diberikan oleh para peserta, maka kegiatan PkM ini dapat disimpulkan berhasil dan bermanfaat bagi para mahasiswa untuk menulis riset penelitian dikemudian hari.

\section{UCAPAN TERIMA KASIH}

Ucapan terima kasih disampaikan kepada Telkomsel yang sudah bersedia mengizinkan kami tim kegiatan untuk menggunakan ruangan kantornya.

\section{DAFTAR PUSTAKA}

Brodjonegoro, Bambang. (2019). Laporan Kinerja. Jurnal Abdimas Dewantara, 53(9), 1689-1699.
Festiyed. (2015). "Kiat dan Tips Sukses Menulis Proposal". Repositori Universitas Negeri Padang, 1(2), 1-13.

Januarius, Fabian. (2019). "Indonesia Posisi Pertama Soal Publikasi Ilmiah Dan Paten Di Asia Tenggara." Kompas.Com. Retrieved November 18, 2020.

Melfianora. (2019). "Penulisan Karya Tulis Ilmiah Dengan Studi Literatur." Open Science Framework, 1(2), 1-3.

Misra. (2010). Peningkatan Kemampuan Menulis Pengumuman Melalui Metode Latihan Siswa Kelas IV SD Inpres 2 Gio Kecamatan Moutong. Jurnal Kreatif Tadulako online, 1(2), 1-14.

Mulia, Vera Dewi, Indra Gunawan, and Suryawati Suryawati. (2018). "Perawatan Pasien Kemoterapi : Strategi Koping Religius dan Menulis Untuk Meningkatkan Kualitas Hidup Care For Chemotherapy Patients : Religious Coping and Writing Strategy To Increase The Quality Of Life." IX(3):57-62.

Rudystina, Adinda. (2020). "6 Manfaat Menulis Setiap Hari Untuk Kesehatan Hello Sehat." Retrieved November 18, 2020. 